\title{
Modeling of subsurface horizontal flow constructed wetlands using OpenFOAM ${ }^{\circledR}$
}

\author{
Rakesh Kadaverugu ${ }^{1}$ (D)
}

Received: 16 March 2016/ Accepted: 16 March 2016/Published online: 28 March 2016

(C) Springer International Publishing Switzerland 2016

\begin{abstract}
Natural purification of pollutants is one of the major ecosystem services provided by wetlands. The phenomenon of natural treatment is exploited by constructing artificial wetlands for the treatment of domestic wastewater. Various wetland models developed in the recent past range from simplistic regression analysis to highly complex deterministic systems. However, these models doesn't suit to the moderate requirements of environmental practitioners for designing appropriate wetland systems. The present model simulates the dynamic behavior of sub-surface horizontal flow wetland systems by considering the non-linear hydrodynamics and pollutant transport, developed in an open source computational fluid dynamics environment-OpenFOAM ${ }^{\circledR}$. The non-linear movement of wastewater in porous media is coupled with the advectiondispersion-decay multi-physics phenomenon of pollutant with temperature dependent rate kinetics. Sensitivity analysis of the model showed that, van Genuchten's filter media shape parameters $\alpha, n$, and decay constant $\lambda$ influences the treatment efficiency of wetlands. Further, the model is useful in visualizing the spatio-temporal profiles of pollutants and hydrodynamics which eventually guide the environmental practitioners in better design of treatment wetland systems.
\end{abstract}

Keywords Constructed wetlands - Mathematical modeling $\cdot$ OpenFOAM $^{\circledR}$. Porous media $\cdot$ Multi-physics phenomenon

Rakesh Kadaverugu

r_kadaverugu@neeri.res.in

1 CSIR-NEERI, Nagpur, Maharashtra, India

\section{Introduction}

Nearly $80 \%$ of the domestic wastewater produced in developing countries is discharged untreated due to under capacity of treatment infrastructure (Qadir et al. 2010; Mara 2013). Wetland treatment technology is matured substantially as an economic alternative in comparison with conventional sewage treatment plants (Haberl 1999; $\mathrm{Naz}$ et al. 2009). Although constructed wetlands (CWs) require large surface area in comparison with conventional treatment units, they offer tremendous potential for the decentralized treatment of community domestic wastewater (Kadaverugu et al. 2016). Natural process of purification in wetlands such as-carbon, nitrogen and sulphur cycles by microbes, sedimentation, filtration and adsorption by filter media (Imfeld et al. 2009; Faulwetter et al. 2009; Vymazal 2008) are being exploited by constructing artificial treatment wetlands with greater control on engineering aspects and treatment efficiency (Vymazal 2005; Langergraber et al. 2009). Based on the water level in CWs relative to the filter media, they are broadly categorized into surface flow or sub-surface flow CWs. Especially subsurface horizontal flow type of CWs are widely used for treating domestic and municipal wastewater (Vymazal 2009). Lot of emphasis is needed in designing CWs by using proper mathematical models, rather than following the rules of thumb. Besides, operation of CWs depends on various parameters such as hydraulic retention time, filter media shape parameters and decay constant of pollutants etc.

Previously developed mathematical tools for investigating efficiency of CWs range from simple regression fit of data to complex deterministic models. Although, Hunt et al. (2002), Rousseau et al. (2004), and Tang et al. (2009) have predicted the performance of $\mathrm{CWs}$ based on 
regression equations, the processes are over simplified by comparing just input and output data rather than modeling the internal processes. The first-order models representing the CWs (for example Sun et al. 2005; Stein et al. 2007) are considered to be better approximation of the complex biological processes (Knight et al. 1999), however their validity is compromised when the system is simplified by compartmentalizing the hydrodynamics. Hence they are not much suitable for designing the CWs. Further in the line of increasing complexity of CWs models, FITOVERT (Giraldi et al. 2010), HYDRUS 2D/3D (Simunek et al. 2008), PHWAT (Brovelli et al. 2009) have managed to tackle the variably saturated hydrodynamics of filter media and also included the biological models for determining the fate of pollutants. However these models are not available as open source software. Although, OpenGeoSys (Kolditz et al. , 2012) is free software for modeling hydro-thermoreactive transportation in rock fractures and porous media, it is in development stage and without much user base. In this junction OpenFOAM ${ }^{\circledR}$ fits aptly with capabilities of programmable multi-physics and having wider acceptability among environmental modeling groups. OpenFOAM ${ }^{\circledR}$ (Open Source Field Operation and Manipulation Jasak et al. 2007; Greenshields 2015) is an open source computational fluid dynamics tool box capable of dealing complex geometries in both space and time, and also enables the unrestricted access to the users and it is modifiable. Thus OpenFOAM ${ }^{\circledR}$ allows a fast circulation of ideas and innovations among various fields of environmental sciences and computational continuum mechanics (Orgogozo et al. 2014).

The paper aims (1) to model a generic sub-surface horizontal flow $\mathrm{CW}$ in OpenFOAM ${ }^{\circledR}$ and (2) to investigate the key parameters which significantly influences its performance. The model couples the variably saturated flow of fluid in filter media with the advection, dispersion and decay of biological pollutants and simulates its spatiotemporal distribution in CWs. This work will enable the environmental practitioners and designers to model their own wetland scenario and helps them to appreciate the role of various sensitive parameters in optimizing the treatment efficiency. Although the study is pertinent to horizontal flow sub-surface CWs, by changing the filter media parameters and boundary conditions the model can mimic soil aquifer treatment units and vertical flow sub-surface wetlands as well.

\section{Modeling approach}

Structure of generic sub-surface horizontal flow CWs is trapezoidal trough (Fig. 1) which is filled with filter media and contains provision for inlet and outlet of wastewater.

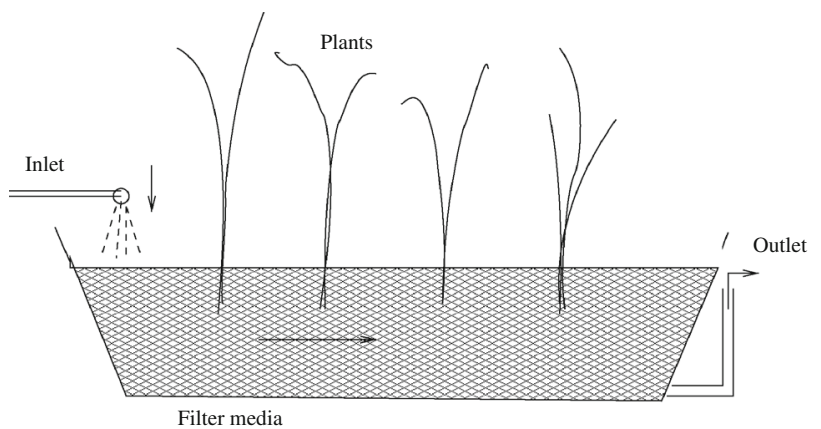

Fig. 1 Typical schematic of horizontal flow sub-surface constructed wetland

Primary treated wastewater enters through inlet and it eventually passes through porous filter media. Meanwhile the pollutants get advected, dispersed (and diffused) and decayed. Flow through porous media is non-linear as the hydraulic conductivity is dependent on saturation of media. Decay of organic pollutants by microbes can be simplified as temperature dependent rate kinetics. These processes are modeled in this work.

\section{Fluid movement}

CWs filter media usually consists of fine sand $(1-2 \mathrm{~mm})$, coarse sand $(2-4.75 \mathrm{~mm})$ or stone chips, which leads to the development of variably saturated conditions, especially at the interface with atmosphere. Fluid movement in the filter media can be represented with Richards equation, which is the combination of Darcy's law and conservation of mass. Richards equation for incompressible and laminar flow is represented as Eq. 1,

$C(h) \frac{\partial h}{\partial t}=\nabla \cdot(K(h) \cdot \nabla(h+z))-F$

where $C$ is the differential water capacity $\left(\mathrm{m}^{-1}\right), h$ is soil water pressure head expressed in length of water column (m), $z$ is the vertical coordinate $(\mathrm{m}), t$ is the time (s), $K$ is the unsaturated hydraulic conductivity as a function of water head $(\mathrm{m} / \mathrm{s})$, and $F$ is the rate of root water extraction per unit volume of media $\left(\mathrm{m}^{3} / \mathrm{m}^{3} / \mathrm{s}\right)$. The process of water uptake by roots is governed by the filter media pressure head profiles, photosynthesis models of vegetation and also dependent on dynamic micro-climatic variables (Kadaverugu 2015). For the sake of simplicity, extraction of water due to roots is not considered. However, it is grossly included in evapo-transpiration losses provided as boundary condition in the Eq. 1.

The relationship between water saturation and water pressure head in filter media and between hydraulic conductivity and saturation are adapted from the van Genuchten and Mualem equations (van Genuchten 1980; Mualem 1976), as shown as in Eq. 2 and 3, 
$S(h)= \begin{cases}\left(1+|\alpha h|^{n}\right)^{-m} & h<0 \\ 1 & h \geq 0\end{cases}$

$K(h)=K_{s} S(h)^{1 / 2}\left[1-\left(1-S(h)^{1 / m}\right)^{m}\right]^{2}$

where $S$ is effective saturation, $K_{s}$ is saturation water conductivity $(\mathrm{m} / \mathrm{s}), \alpha$ is a parameter used to scale the matric pressure head $\left(\mathrm{m}^{-1}\right), m$ and $n\left(m=1-\frac{1}{n}\right)$ are a dimensionless parameter related to width of pore size distribution of filter media. Water capacity, $C(h)$ can be derived from Eqs. 4 and 5,

$$
\begin{aligned}
& \theta(h)=\theta_{r}+\left(\theta_{s}-\theta_{r}\right) S(h) \\
& C(h)=\frac{d \theta(h)}{d h} \\
& C(h)=\left(\theta_{s}-\theta_{r}\right)\left[-m\left(1+|\alpha h|^{n}\right)^{-m-1}\right]\left[n|\alpha h|^{n-1} \alpha\right] .
\end{aligned}
$$

where, $\theta_{r}$ is residual water content, $\theta_{s}$ is saturated water content and $\theta$ is water volumetric water content $\left(\mathrm{m}^{3} / \mathrm{m}^{3}\right)$. The expressions of $C(h)$ and $K(h)$ are substituted in Eq. 1, which can be solved in OpenFOAM ${ }^{\circledR}$ (for detailed numerical solution, Kadaverugu 2015 may be referred).

\section{Transport of pollutants}

Pollutants get carried away due to the seepage velocity of fluid passing through macro pores of the filter media. Due to the velocity of fluid and due to the differences in concentration gradient, pollutants are advected, diffused and dispersed. Dispersion includes the mechanical dispersion of pollutants due to local variations in velocity of flow and molecular diffusion of pollutants. The effect of water content on pollutant transport and the phenomenon of adsorption, filtration and sedimentation are not considered in the present model, however the model paves the background for future works in this regard. Conservation of mass of pollutant in the filter media matrix leads to the advection-dispersion-decay equation, as shown in Eq. 7,

$$
\begin{aligned}
& \frac{\partial P}{\partial t}+\nabla \cdot(\mathbf{U} P)=D_{P} \nabla^{2} P-R(P, T) \\
& D_{P}=D_{m} \tau+d \cdot \mathbf{U}
\end{aligned}
$$

where $P$ is the concentration of pollutant $\left(\mathrm{kg} / \mathrm{m}^{3}\right), R$ is reaction term of the pollutant which is dependent on space, time , $P$ and temperature of fluid $T(\mathrm{~K}), D_{P}$ is dispersion coefficient of the pollutant $\left(\mathrm{m}^{2} / \mathrm{s}\right), D_{m}$ is molecular diffusion coefficient $\left(\mathrm{m}^{2} / \mathrm{s}\right), \tau$ is tortuosity factor, $d$ is dispersivity (m) with longitudinal and transverse components $d_{l}$ and $d_{t}$, and $\mathbf{U}$ is the velocity vector $(\mathrm{m} / \mathrm{s})$. The expression for $\mathbf{U}$ is derived from Darcy's law
$\mathbf{U}=-\frac{K(h)}{\eta} \nabla(h+z)$

where, $\eta$ is the filter media porosity.

\section{Transport of temperature}

Temperature plays an important role in governing the microbial activity Wynn and Liehr (2001) which would directly influence the rate kinetics of organic pollutants decay. Inlet water carries the temperature into the system and leaves through outlet. The loss of heat due to evapotranspiration and convection with the ambient atmosphere is not considered. The temperature transportation of the system is governed by the Eq. 10,

$$
\frac{\partial T}{\partial t}+\nabla \cdot(\mathbf{U} T)=D_{T} \nabla^{2} T
$$

where $D_{T}$ is temperature diffusion coefficient $\left(\mathrm{m}^{2} / \mathrm{s}\right)$.

\section{Pollutant decay}

Various experiments have suggested that the organic pollutants removal is better approximated by the exponential decay (Knight et al. 1999; Liolios et al. 2012). Temperature dependent rate kinetics of organic pollutants term in Eq. 7 can be presented as,

$$
\begin{aligned}
& R(P, T)=\lambda P \\
& \lambda=\lambda_{20} \phi^{(T-20)}
\end{aligned}
$$

where, $\lambda$ is temperature dependent rate constant $\left(\mathrm{s}^{-1}\right), \lambda_{20}$ is rate constant at $20^{\circ}\left(\mathrm{s}^{-1}\right), \phi$ is a dimensionless temperature correction factor (Tanner et al. 1995).

Clogging of filter media due to the biological process is a longterm phenomenon (Knowles et al. 2011) which is not considered in the present model, as the scope of the model is to simulate dynamic profiles of pollutants in short time scales. However, various mechanistic models for simulating the clogging behavior (for example Hyánková et al. 2006; Hua et al. 2010) have achieved mixed degrees of success (Nivala et al. 2012) and they are still in the development stage. Further, the effects of climatic conditions (such as changes in temperature, humidity and rainfall etc) on performance of CWs can also be studied.

\section{Materials and methods}

\section{Geometry of CW}

$\mathrm{CW}$ with trapezoidal trough of $6 \mathrm{~m}$ length on top and $4 \mathrm{~m}$ on bottom ( $x$-axis), with $1.5 \mathrm{~m}$ height (z-axis) and $1.0 \mathrm{~m}$ width ( $y$-axis) is considered and having a ' $L$ ' shaped 
Fig. 2 3-Dimensional computational grid of the constructed wetland geometry

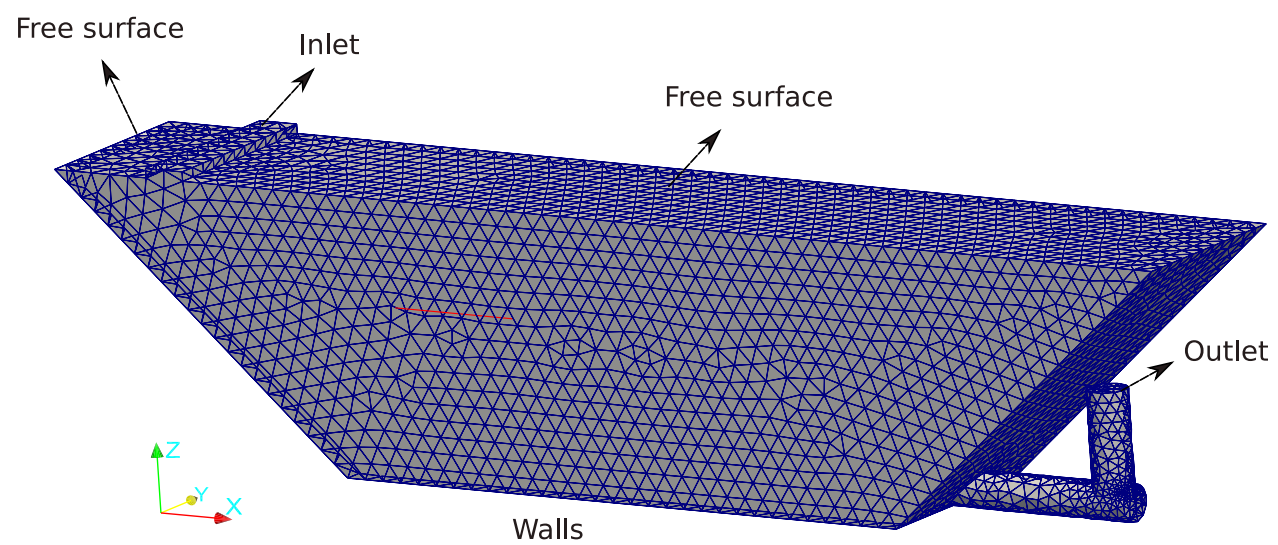

structure as the outlet. Slope of $1 \%$ is considered in the longitudinal direction for the gravity flow. The solid geometry of CW is developed in OpenSCAD (Kintel and Wolf 2014) and its tetrahedron meshing is done in NETGEN (Schöberl 2004), both are open-source software. The mesh diagnostics are performed to remove all the nonorthogonality errors. The unstructured computational mesh of CW with 25277 cells and 6124 points is shown in Fig. 2, indicating the boundary names viz. input, outlet, free surface (open to atmosphere) and walls.

\section{Input data}

The filter media is considered to be sandy gravel with particle size of 2-5 $\mathrm{mm}$. The constants / parameters defining the flow and pollutant transport used in the model simulations is presented in Table 1, which are gathered from the pertinent literature. The Dirichlet and Newmann type of boundary conditions for the inlet, outlet, walls and free surface of the computational grid are presented in Table 2 using OpenFOAM ${ }^{\circledR}$ keywords, which are self explanatory. Evapotranspiration losses are included at the free surface boundary and $\mathrm{CW}$ inlet water temperature is provided as a time dependent variable (function of sine) to mimic the diurnal variations. Inlet concentration of organic pollutant (biological oxygen demand, BOD) is kept constant throughout the simulation. No-slip boundary condition is assigned for the velocity at the walls of the structure.

\section{Solution schemes}

Non-linear movement of fluid in the filter media is coupled with the advection-dispersion-decay phenomenon of pollutants in OpenFOAM environment. Orgogozo et al. (2014) have developed the RichardsFoam solver in OpenFOAM $^{\circledR}$, which solves the Richards equation (Eq. 1) to simulate the pressure head, $h$ and water saturation content, $\theta$. The simulated values of $h$ by RichardsFoam
Table 1 Constants/parameters of constructed wetland used in the model simulations

\begin{tabular}{llll}
\hline Parameter & Value & Unit & Source \\
\hline Porosity, $\eta$ & $\sim 11$ & $\%$ & Considered \\
Particle size, sandy-gravel, $d_{f}$ & $2-5$ & $\mathrm{~mm}$ & Considered \\
Initial water head profile & -1 & $\mathrm{~m}$ & Considered \\
Initial water temperature profile & 293 & $\mathrm{~K}$ & Considered \\
Pollutant diffusion coefficient, $D_{m}$ & $1.4 \times 10^{-7}$ & $\mathrm{~m}^{2} / \mathrm{s}$ & Toscano et al. (2009) \\
Tortuosity, $\tau$ & 0.5 & - & Wen-Ling et al. (2011) \\
Longitudinal dispersivity, $d_{l}$ & 0.45 & $\mathrm{~m}$ & Toscano et al. (2009) \\
Transverse dispersivity, $d_{t}$ & 0.10 & $\mathrm{~m}$ & Toscano et al. (2009) \\
Thermal diffusion coefficient, $D_{T}$ & $1.43 \times 10^{-7}$ & $\mathrm{~m}^{2} / \mathrm{s}$ & Blumm and Lindemann (2003) \\
Rate constant at 20 $0^{\text {circ }}, \lambda_{20}$ & 0.22 & $\mathrm{~d}^{-1}$ & Liolios et al. (2012) \\
Temperature correction factor, $\phi$ & 1.06 & - & Liolios et al. (2012) \\
Saturation hydraulic conductivity, $K_{s}$ & 0.0013 & $\mathrm{~m}^{\prime} / \mathrm{s}$ & Khaleel and Freeman (1995) \\
Shape parameter, $\alpha$ & 2.8 & $\mathrm{~m}^{-1}$ & Khaleel and Freeman (1995) \\
Shape parameter, $n$ & 1.885 & - & Khaleel and Freeman (1995) \\
Residual water content, $\theta_{r}$ & 0.028 & $\mathrm{~m}^{-3} / \mathrm{m}^{-3}$ & Khaleel and Freeman (1995) \\
Saturated water content, $\theta_{s}$ & 0.107 & $\mathrm{~m}^{-3} / \mathrm{m}^{-3}$ & Khaleel and Freeman (1995) \\
\hline
\end{tabular}


Table 2 Boundary conditions for the model simulations mentioned in OpenFOAM ${ }^{\circledR}$ keywords.

\begin{tabular}{|c|c|c|c|}
\hline Variable & Boundary type & OpenFOAM boundary conditions & Value \\
\hline \multirow[t]{4}{*}{ Temperature, $T$} & Inlet & uniformFixedValue & $293+15 \times\left|\sin \left(\frac{\pi \times t}{3600 \times 24}\right)\right| K$ \\
\hline & Outlet & zeroGradient & \\
\hline & Free surface & zeroGradient & \\
\hline & Walls & zeroGradient & \\
\hline \multirow[t]{4}{*}{ Pollutant, $P$} & Inlet & fixedValue & $0.1 \mathrm{~kg} / \mathrm{m}^{3}$ \\
\hline & Outlet & zeroGradient & \\
\hline & Free surface & zeroGradient & \\
\hline & Walls & zeroGradient & \\
\hline \multirow[t]{4}{*}{ Water pressure head, $h$} & Inlet & fixedValue & $0.01 \mathrm{~m}$ \\
\hline & Outlet & zeroGradient & \\
\hline & Free surface & fixedGradient & $-0.005 \mathrm{~m} / \mathrm{m}$ \\
\hline & Walls & zeroGradient & \\
\hline \multirow[t]{4}{*}{ Velocity, $\mathbf{U}$} & Inlet & zeroGradient & \\
\hline & Outlet & zeroGradient & \\
\hline & Free surface & zeroGradient & \\
\hline & Walls & fixedValue & $0 \mathrm{~m} / \mathrm{s}$ \\
\hline
\end{tabular}

Fig. 3 Temporal profile of variables developed at the outlet point of the constructed wetland for a Pollutant concentration, $P$, b Temperature, $T$, c Pressure head, $h$ and $\mathbf{d}$ Water content, $\theta$
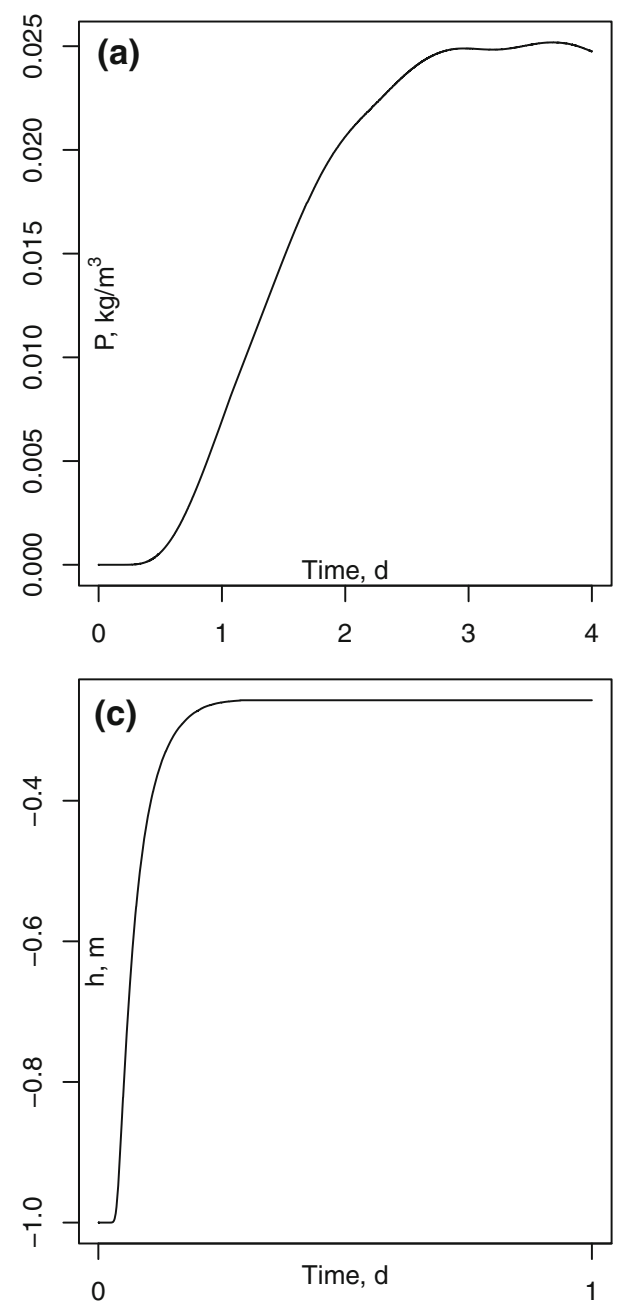
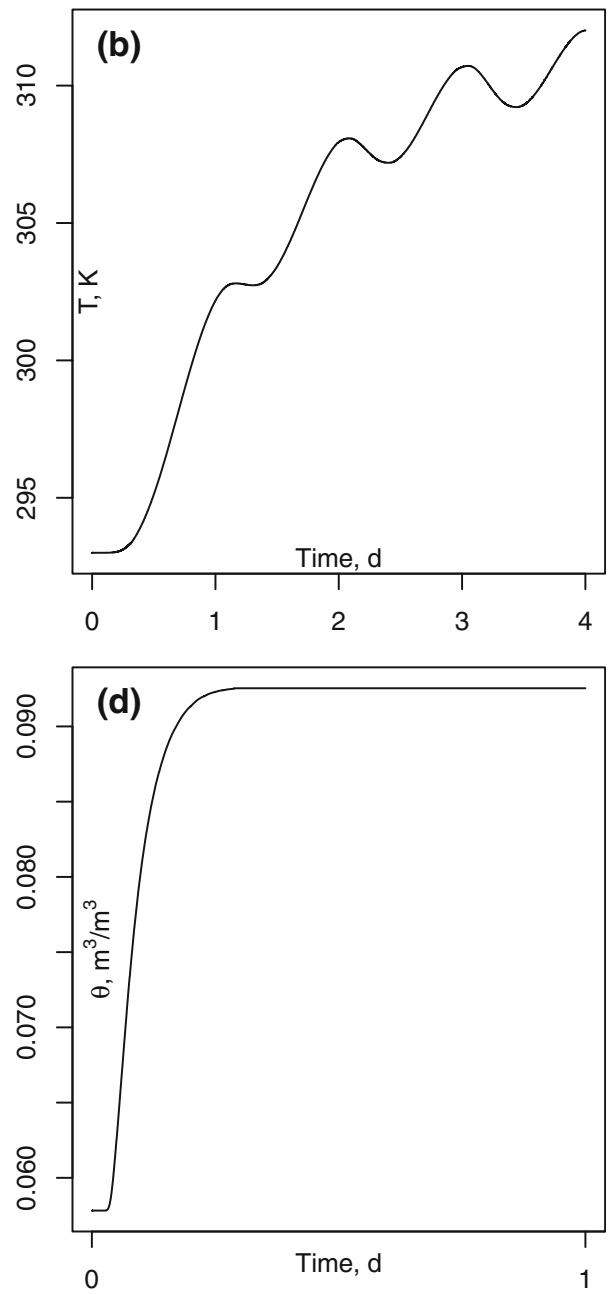
Fig. 4 Spatial profile of pollutant concentration, $P$ shown along the lateral section of the constructed wetland after a $1 \mathrm{~h}, \mathbf{b} 12 \mathrm{~h}$ and c 1 day retention time

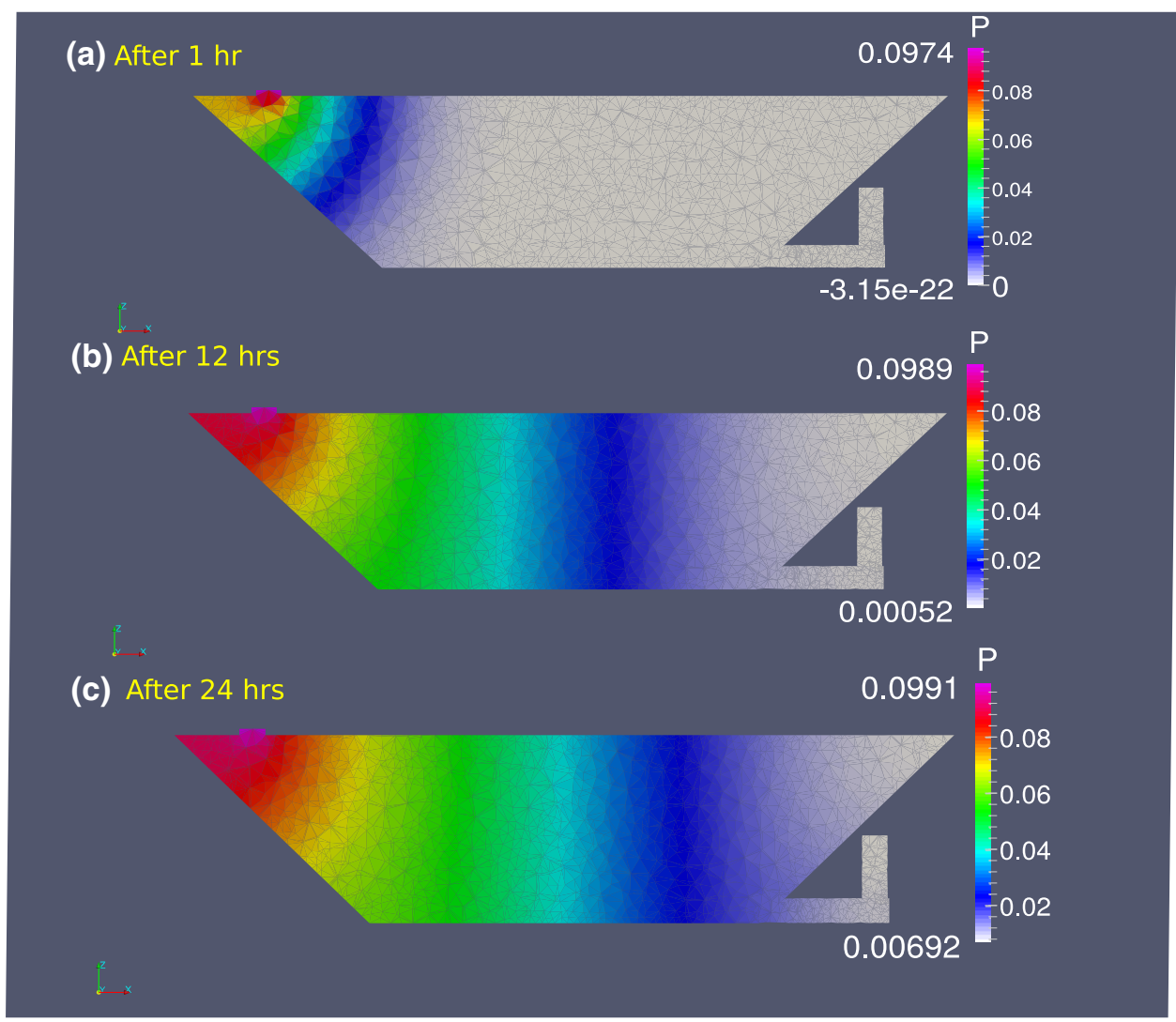

solver for a flow through column was however validated with HYDRUS-1D simulations (Orgogozo et al. 2014). The solver is modified in this study to accommodate the dynamics of pollutant concentration, $P$ (Eq. 7, 11) and temperature, $T$ (Eq. 10). The equations are programmed in OpenFOAM $^{\circledR}$ syntax, which uses finite volume method for solving the mentioned differential equations. The gradients in the equations are discretized by Gauss linear schemes, divergence by Gauss linear upwind schemes and the laplacian terms are discretized using Gauss linear method. Pressure head, $h$ is solved by PCG solver, $P$ and $T$ are solved by PBiCG solvers of OpenFOAM ${ }^{\circledR}$.

Post-processing of the OpenFOAM simulation data is carried out in an open-source software ParaView (Ahrens et al. 2005) and graphs are developed in R-statistics ( $R$ Development Core Team 2008).

\section{Results and discussion}

The model was run for 4 days (from the beginning for the first time) with a time step of $60 \mathrm{~s}$ to simulate the spatiotemporal profiles of water content, $\theta$, velocity field, $\mathbf{U}$, pollutant concentration, $P$, fluid temperature, $T$ and water pressure head, $h$.

\section{Hydrodynamics and pollutant profile}

The temporal profiles of water content, $\theta$ and pressure head, $h$ at the outlet of CW attains near constant after $\sim 10$ $\mathrm{h}$ from the starting time, which shows that the filter media is saturated (Fig. 3c, d). However, the pollutant concentration takes sufficient time of $\sim 2.5$ days to reach the near constant conditions at the outlet (Fig. 3a). Initially the $P$ values ascend with respect to the time at the outlet due to the diffusion and dispersion transport, however after 2.5 days, the concentration is almost constant due to the dominance of reaction term, which can be interpreted as treatment efficiency. The $\mathrm{CW}$ with the provided conditions has a treatment efficiency of $75 \%$ as calculated in Eq. 12 .

$$
\begin{aligned}
\text { Efficiency } & =\frac{\left(P_{\text {inlet }}-P_{\text {outlet }}\right)}{P_{\text {inlet }}} \times 100 \\
& =\frac{(0.1-0.025)}{0.1} \times 100 \\
& =75 \%
\end{aligned}
$$

The gradual temporal development of pollutant concentration along the lateral section at time $t=1,12$ and $24 \mathrm{~h}$ is shown Fig. 4. The inlet portion displays the intense dispersion of concentration due to high seepage velocities and non-linearity of hydraulic conductivity. Later on the concentration travels 
Fig. 5 Spatial profile of variables a magnitude of velocity $\mathbf{U}, \mathbf{b}$ pollutant concentration $P, \mathbf{c}$ water content $\theta$ and $\mathbf{d}$ water temperature $T$ after 3 days of retention time along the lateral section of the constructed wetland

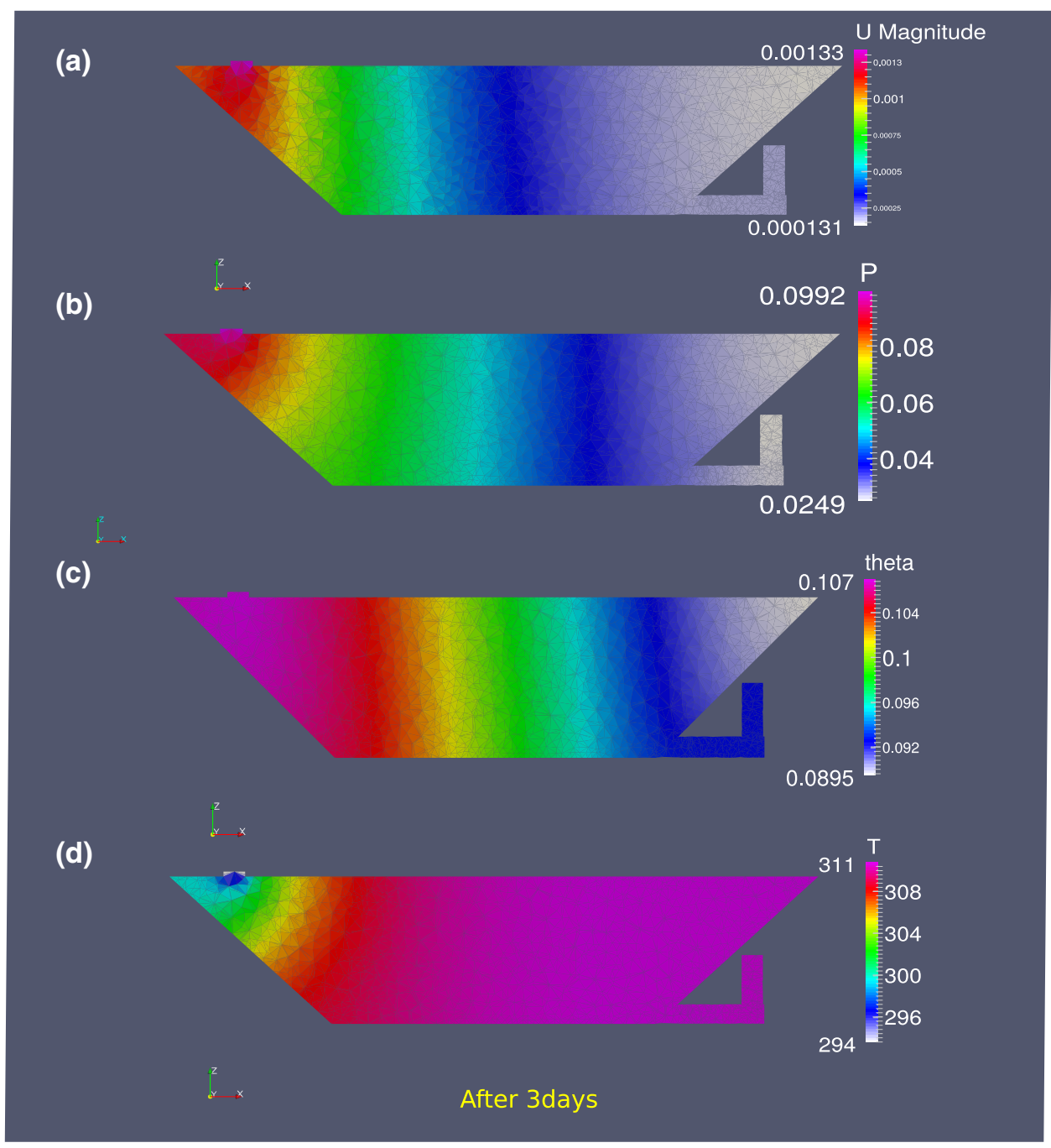

uniformly in a near horizontal profile towards the outlet due to the influence of residence time which causes the decay of $P$ and also due to lower magnitude of $\mathbf{U}$.

The fully developed spatial profiles of $P, \mathbf{U}, T$ and $\theta$ after 3 days of retention time are presented in Fig. 5. The maximum Reynolds number, $R_{e} \approx 4$ is noted at the inlet zone of the wetland trough, thus validates the laminar flow assumption throughout the simulations. Darcy's law is valid for the laminar flow of fluids dominated by viscous forces. Various studies have shown that Reynolds number $R_{e} \leq 10$ can be acceptable for considering the flow through porous media as laminar (Bear 1972). The expression for $R_{e}$ is shown in Eq. 13,

$R_{e}=\frac{\rho v d_{f}}{\mu}$

where $\rho$ is density of fluid $\left(\mathrm{kg} / \mathrm{m}^{3}\right), v$ is specific discharge $(\mathrm{m} / \mathrm{s}), d_{f}$ is mean diameter of filter particles and $\mu$ is dynamic viscosity of fluid (Pa-s).
The water content, $\theta$ also develops a gradual spatiotemporal profile. A marginal difference between the $\theta_{\text {inlet }}=\theta_{s}=0.107$ and $\theta_{\text {outlet }} \approx 0.095$ is evident (Fig. 5c), which is may be due to significant evapo-transpiration losses (provided at free surface boundary). Nearly $12.5 \%$ volume of the $\mathrm{CW}$ with the present geometry is estimated as dead zone with $\theta \leq 0.092$, which is developed at the top right portion. The dead zone of the filter media is where the media is not completely saturated or doesn't participate in the treatment process. Further, with the help of the presented modeling approach, various geometries of CWs can be evaluated for minimizing the dead zones.

The water temperature displays an increasing wavy pattern (Fig. 3b), as the inlet boundary condition for $T$ is provided in the form of sine function (Table 2). Similarly, the temperature profile in Fig. $5 d$ at the completion of $3^{\text {rd }}$ day of retention time has cooler inlet than the middle and outlet portions of CWs. 
Fig. 6 Sensitivity coefficient $\Delta P_{p}$ of the model for different parameters $p=\alpha, n, K_{s}$, and $\lambda$
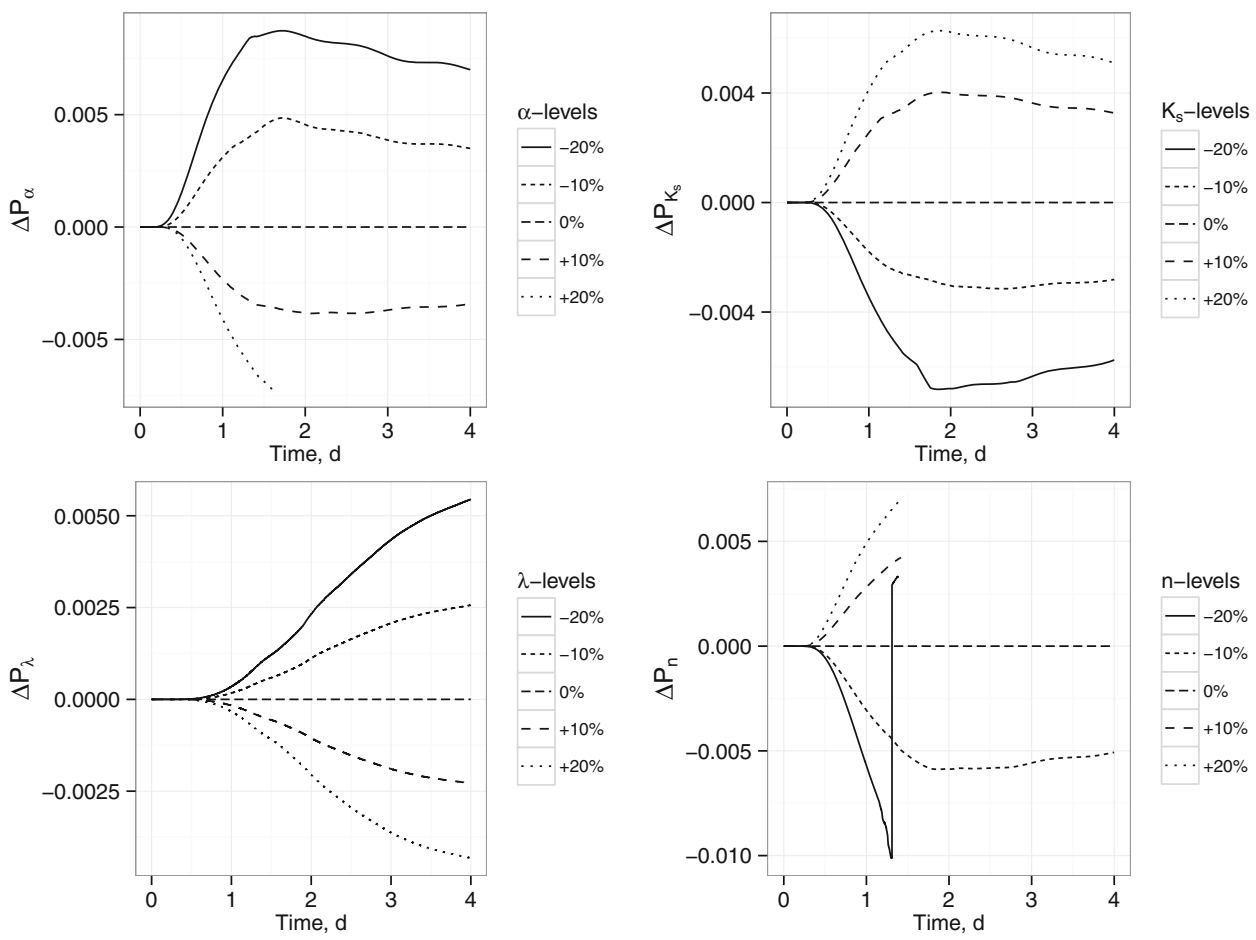

\section{Sensitivity analysis}

Sensitivity analysis of the model is performed by varying the filter media parameters and rate constant viz. $\alpha, n, K_{s}$, and $\lambda$ (wherein $\lambda$ is a figurative representation of $\lambda_{20}$ ). The model response is measured in terms of temporal variation of outlet pollutant concentration. The temporal profile of pollutant concentration obtained with respect to the initially provided values of model parameters (Table 1) is taken as reference (Fig. 3a). Deviation of pollutant concentration, $P$ relative to the reference pollutant concentration $P_{r}$ is evaluated using the sensitivity coefficient, $\Delta P_{p}$ at each time step, $t$,

$$
\Delta P_{p, l}(t)=P_{p, l}(t)-P_{r}(t)
$$

where, $P_{p, l}$ is the pollutant concentration at different parameters, $p=\alpha, n, K_{s}$, and $\lambda$, and $l=$ level of variation in $p$. The parameter levels are varied by \pm 10 and $\pm 20 \%$ of the reference values (mentioned in Table 1).

The model response in terms $\Delta P_{p}$ (Fig. 6) is most sensitive to the filter media shape parameter $n$ and decay constant $\lambda$. Liolios et al. (2012) have also noted the influence of decay constant on wetland model performance. Incidents of non-convergence are noticed while performing the simulations at $n$ equal to 2.0735 (at $+10 \%$ ), 2.262 (at $+20 \%$ ) and 1.508 (at $-20 \%$ ). Whereas, due to the reduction of $\lambda$ by $20 \%$ (at $\lambda=0.176$ ) the values of sensitivity coefficient $\Delta P_{\lambda}$ shoots upwards resulting the lower reduction of removal efficiency. Almost symmetric behavior is observed with the variations in $\alpha$ and $K_{s}$ with respect to the reference trend, with positive relation between $K_{s}$ and $\Delta P_{K_{s}}$ and negative relation between $\alpha$ and $\Delta P_{\alpha}$.

\section{Conclusion}

Understanding about hydrodynamics and pollutant transport of constructed wetlands is essential for the full scale utilization of these units for decentralized wastewater treatment. The model presented in this work, guides the environmental modeling groups to simulate their own wetland land system using open-source computational fluid dynamics software OpenFOAM ${ }^{\circledR}$. The model helps to visualize the transport of pollutants and highlights the sensitive parameters which significantly affects the system efficiency. Various simulations run by the model shows that, wetland efficiency is sensitive to filter media shape parameter and decay constant. Further, the model can be extended to include nutrient cycles, role of microbes, plant interactions and influence of climatic variables, which will be of future interest.

Acknowledgements I am thankful to Dr. Ashok, Mrs. Pratyusha Suresh and Ms. Srija for encouraging this work. I acknowledge the institutional support provided by CSIR-National Environmental Engineering Research Institute, India. 


\section{Compliance with ethical standards}

Conflict of interest No financial interest or benefit is intended from the direct applications of this research. Author declares that there is no conflict of interest with any person or organization.

\section{References}

Ahrens J, Geveci B, Law C (2005) ParaView: an end-user tool for large-data visualization, chap 36. In: Hansen CD, Johnson CR (eds) The visualization handbook. Elsevier, Burlington, MA, pp 717-731

Bear J (1972) Dynamics of fluids in porous media. Elsevier, New York $764 \mathrm{p}$

Blumm J, Lindemann A (2003) Characterization of the thermophysical properties of molten polymers and liquids using the flash technique. High Temp High Press 35(36):6

Brovelli A, Malaguerra F, Barry D (2009) Bioclogging in porous media: model development and sensitivity to initial conditions. Environ Modell Softw 24(5):611-626

Faulwetter JL, Gagnon V, Sundberg C, Chazarenc F, Burr MD, Brisson J, Camper AK, Stein OR (2009) Microbial processes influencing performance of treatment wetlands: a review. Ecol Eng 35(6): $987-1004$

Giraldi D, de Michieli Vitturi M, Iannelli R (2010) Fitovert: a dynamic numerical model of subsurface vertical flow constructed wetlands. Environ Modell Softw 25(5):633-640

Greenshields CJ (2015) OpenFOAM-The Open Source CFD Toolbox-User Guide. OpenFOAM Foundation Ltd., version 2.4.0 edn. http://www.openfoam.org

Haberl R (1999) Constructed wetlands: a chance to solve wastewater problems in developing countries. Water Sci Technol 40(3):11-17

Hua G, Zhu W, Zhang Y (2010) A conceptual approach based on suspended solids to estimate clogging time in constructed wetlands. J Environ Sci Health Part A 45(12):1519-1525

Hunt P, Szögi A, Humenik F, Rice J, Matheny T, Stone K (2002) Constructed wetlands for treatment of swine wastewater from an anaerobic lagoon. Trans ASAE 45(3):639-647

Hyánková E, Kriška-Dunajskỳ M, Rozkošnỳ M, Sálek J (2006) The knowledge based on the research of the filtration properties of the filter media and on the determination of clogging causes. In: Proceedings of the 10th International Conference on Wetland Systems for Water Pollution Control, pp 23-29

Imfeld G, Braeckevelt M, Kuschk P, Richnow HH (2009) Monitoring and assessing processes of organic chemicals removal in constructed wetlands. Chemosphere 74(3):349-362

Jasak H, Jemcov A, Tukovic Z (2007) Openfoam: a c++ library for complex physics simulations. International workshop on coupled methods in numerical dynamics. vol 1000, pp 1-20

Kadaverugu R (2015) Framework for mathematical modeling of soiltree system. Model Earth Syst Environ 1(3):17. doi:10.1007/ s40808-015-0017-2

Kadaverugu R, Shingare RP, Raghunathan K, Juwarkar AA, Thawale PR, Singh SK (2016) The role of sand, marble chips and typha latifolia in domestic wastewater treatment: a column study on constructed wetlands. Environ Technol 0(0):1-8. doi:10.1080/ 09593330.2016.1153156 (pMID: 26878342)

Khaleel R, Freeman E (1995) Variability and scaling of hydraulic properties for 200 area soils, hanford site. Westinghouse Hanford Company Report WHC-EP-0883

Kintel M, Wolf C (2014) Openscad. GNU General Public License, p GNU General Public License
Knight RL, Kadlec RH, Ohlendorf HM (1999) The use of treatment wetlands for petroleum industry effluents. Environ Sci Technol 33(7):973-980

Knowles P, Dotro G, Nivala J, García J (2011) Clogging in subsurface-flow treatment wetlands: occurrence and contributing factors. Ecol Eng 37(2):99-112

Kolditz O, Bauer S, Bilke L, Böttcher N, Delfs JO, Fischer T, Görke UJ, Kalbacher T, Kosakowski G, McDermott C et al (2012) Opengeosys: an open-source initiative for numerical simulation of thermo-hydro-mechanical/chemical (thm/c) processes in porous media. Environ Earth Sci 67(2):589-599

Langergraber G, Giraldi D, Mena J, Meyer D, Peña M, Toscano A, Brovelli A, Korkusuz EA (2009) Recent developments in numerical modelling of subsurface flow constructed wetlands. Sci Total Environ 407(13):3931-3943

Liolios KA, Moutsopoulos KN, Tsihrintzis VA (2012) Modeling of flow and bod fate in horizontal subsurface flow constructed wetlands. Chem Eng J 200:681-693

Mara D (2013) Domestic wastewater treatment in developing countries. Routledge, Sterling, VA

Mualem Y (1976) A new model for predicting the hydraulic conductivity of unsaturated porous media. Water Resour Res 12(3):513-522

Naz M, Uyanik S, Yesilnacar MI, Sahinkaya E (2009) Side-by-side comparison of horizontal subsurface flow and free water surface flow constructed wetlands and artificial neural network (ann) modelling approach. Ecol Eng 35(8):1255-1263

Nivala J, Knowles P, Dotro G, García J, Wallace S (2012) Clogging in subsurface-flow treatment wetlands: measurement, modeling and management. Water Res 46(6):1625-1640

Orgogozo L, Renon N, Soulaine C, Hénon F, Tomer SK, Labat D, Pokrovsky OS, Sekhar M, Ababou R, Quintard M (2014) An open source massively parallel solver for richards equation: mechanistic modelling of water fluxes at the watershed scale. Comput Phys Commun 185(12):3358-3371

Qadir M, Wichelns D, Raschid-Sally L, McCornick PG, Drechsel P, Bahri A, Minhas P (2010) The challenges of wastewater irrigation in developing countries. Agric Water Manag 97(4):561-568

R Development Core Team (2008) R: a language and environment for statistical computing. R Foundation for Statistical Computing, Vienna, Austria. http://www.R-project.org, ISBN 3-900051-07-0

Rousseau DP, Vanrolleghem PA, De Pauw N (2004) Model-based design of horizontal subsurface flow constructed treatment wetlands: a review. Water Res 38(6):1484-1493

Schöberl J (2004) Netgen-4.3. Reference Manual, January

Simunek J, van Genuchten MT, Sejna M (2008) Development and applications of the hydrus and stanmod software packages and related codes. Vadose Zone J 7(2):587-600

Stein O, Towler B, Hook P, Biederman J (2007) On fitting the $\mathrm{kc}^{*}$ first order model to batch loaded sub-surface treatment wetlands. Water Sci Technol 56(3):93-99

Sun G, Zhao Y, Allen S (2005) Enhanced removal of organic matter and ammoniacal-nitrogen in a column experiment of tidal flow constructed wetland system. J Biotechnol 115(2):189-197

Tang X, Eke PE, Scholz M, Huang S (2009) Processes impacting on benzene removal in vertical-flow constructed wetlands. Bioresour Technol 100(1):227-234

Tanner CC, Clayton JS, Upsdell MP (1995) Effect of loading rate and planting on treatment of dairy farm wastewaters in constructed wetlands I. removal of oxygen demand, suspended solids and faecal coliforms. Water Res 29(1):17-26

Toscano A, Langergraber G, Consoli S, Cirelli GL (2009) Modelling pollutant removal in a pilot-scale two-stage subsurface flow constructed wetlands. Ecol Eng 35(2):281-289 
van Genuchten M (1980) A closed-form equation for predicting the hydraulic conductivity of unsaturated soils. Soil Sci Soc Am J 44:892-898

Vymazal J (2005) Horizontal sub-surface flow and hybrid constructed wetlands systems for wastewater treatment. Ecol Eng 25(5):478-490

Vymazal J (2008) Constructed wetlands for wastewater treatment: a review. In: Proceedings of Taal 2007: The 12th World Lake Conference. pp 965-980
Vymazal J (2009) The use constructed wetlands with horizontal subsurface flow for various types of wastewater. Ecol Eng 35(1): $1-17$

Wen-Ling Z, Li-Hua C, Ouyang Y, Cui-Fen L, Xiao-Dan T (2011) Kinetic adsorption of ammonium nitrogen by substrate materials for constructed wetlands. Pedosphere 21(4):454-463

Wynn TM, Liehr SK (2001) Development of a constructed subsurface-flow wetland simulation model. Ecol Eng 16(4):519-536 